\title{
Roadmap for Smart Metering Deployment in Cameroon
}

\author{
YEM SOUHE Felix*(iD), BOUM Alexandre Teplaira**:(iD), MBEY Camille Franklin***(iD \\ *Department of Electrical Engineering, ENSET, University of Douala, 1872 Douala-Cameroun \\ **Department of Electrical Engineering, ENSET, University of Douala, 1872 Douala-Cameroun \\ ***Department of Electrical Engineering, ENSET, University of Douala, 1872 Douala-Cameroun
}

(felixyem@yahoo.fr, boumat2002@yahoo.fr, camillembey@yahoo.fr)

${ }^{\ddagger}$ BOUM Alexandre Teplaira; 1872 Douala-Cameroun, Tel: +237 675014 572,

Fax:+237675014 572, boumat2002@yahoo.fr

Received: 07.03.2021 Accepted:30.03.2021

\begin{abstract}
This paper is about the elaboration of a roadmap that will help move from classical metering systems to smart metering in Cameroon. The problems encounter in the classical metering systems being the errors in index reading, the billing by estimation and the frauds, the smart metering can be of interest in solving these problems. The goal of this paper is to propose to those in charge with the energy policy of Cameroon, a guide for the deployment of a smart metering system. The meeting with authorities, the annual report of the energy distribution company, the implementation in other countries and the documentations of development strategy in Cameroon, allow us to elaborate a roadmap for smart metering in Cameroon. This roadmap is divided into two phases resumed as follows: the first phase consists to put in place a national monitoring committee, its functional organization chart, and its missions; the second phase is the deployment of equipment. We will start in large cities, followed by medium cities and end with smaller cities. This roadmap could serve as a guide to deploy smart meters in the Central Africa sub-region.
\end{abstract}

Keywords Smart meter, classical metering, roadmap, deployment.

\section{Introduction}

Cameroon is located in central Africa, inside Guinea golf. Cameroon covers $475440 \mathrm{~km} 2$ between Chad in North and Atlantic Ocean in South. Facing a growing demand for electricity in developing countries particularly in Cameroon, the number of subscribers is estimated at around 2500000 in 2035 against 1250000 now [1].

The existing distribution network of Cameroon is a radial network where there is not looping possibility. On the other hand, the fault research is complex and needs a lot of work because there is no possibility for fast detection of fault; it increases the repartition period and non-distributed energies. Moreover, there is not yet a communication system in the distribution network. The managing is done on a map in the monitoring centre of the distribution network. Some types of equipment are remotely controllable including circuit breakers in distribution networks and they are placed in major nodes. The average outage time is 97.65 hours/year and the satisfactory index is $67 \%$. The electrical distribution is done through the source substations on $30 \mathrm{kV}$ in longdistance and $15 \mathrm{kV}$ in the urban area. The electrical grid in Cameroon presents a lot of problems in the energy distribution in term of quality: the impossibility to reconfigure the grid in case of fault; the impossibility to detect the fault in real-time; the impossibility to integrate the distributed generation; the impossibility for the consumer to control and monitor its consumption [2]. The change from classical metering to smart metering is an appropriate solution to resolve the problems presented in [2].

This change passes through the smart meter that is an important element in a smart grid system. We should also have for the structural part, the programming interfaces, the command devices, and the communication system. The deployment of the smart meter is the main goal of our work. The distribution network is strongly dominated by a classical metering system for all consumers. Moreover, with the evolution of digital technologies, the metering in Cameroon has progressed with the use of electronic and prepaid meters. Until now, smart meters are only used in some industries. 
That shows the limits of present energy metering in the distribution network of Cameroon. This kind of metering presents a lot of inconveniences as follows: the impossibility for the consumers to participate in their billing; the error in index reading; billing by estimation. The existing meters are unidirectional; they don't allow consumers to become actors of the network. The absence of communication network and the data processing, the absence of automatic control devices don't allow reconfiguration of the network when a fault occurs; to detect the fault in real-time on distribution network; to control and monitor the consumption. The smart meter is an advanced energy meter that measures electrical energy consumption by providing more information than a conventional energy meter (electro-mechanic) [3]. The integration of communicating prepaid or post-paid meter, around 4000 prepaid meters until now. The installation agenda of communicating meters (post-paid and prepaid) is in course. It allows warranting better reliable metering and more autonomy for customers. It is necessary to install the communicating meters to replace the existing electromechanical metering. The new systems can measure energy consumption by bringing more information than classical meters. They can transmit and receive remotely the data's in the network. This advanced technology is bringing more advantages to customers. Globally, this system offers the possibility for a regular and reliable measure of electrical consumption, to eliminate the reading intervention, and to ensure a permanent distribution of bills to reduce the risk of contestation [2]. B. A. Abedalsalam et al [4] presented a compilation of smart grid technologies and future trends within the communications and computing. In their article, they incorporated in smart grid an advanced networking technology, including sensors and controls that make it possible to monitor electricity use in real time and make automated control to optimize the operation economically and environmentally. Then, the massive amount of data transmitted over the network requires high availability of the system.

There are several definitions of "Smart Grid", for example, the definition of the European Union, Smart Grid is an electricity network that can intelligently integrate the behaviours and actions of all users to ensure the supply of electricity sustainable, economical, and secure electricity [5]. While the US Department of Energy indicates that the Smart Grid is a grid that uses digital technology to improve the reliability, safety and efficiency of the electricity system [6]. Globally, the Smart Grid is the new generation of the power grid that combines advanced communication technologies and electrical technologies. The smart grid also facilitates the integration of renewable energy sources into the electricity grid and the empowerment of consumers with tools to observe the variation and optimization of their energy consumption in real-time [5, 7]. S. N. Saxena [8] presented different aspects of a Smart Distribution Grid. In this paper he discusses the essential technological requirements of a smart grid, which are: Smart Meters, Information and Communication Technology, Advanced Demand-Side Management, Virtual Power Plant, Distributed Generation, Battery Energy Storage, Vehicle-to-Grid System and Operation of Electricity Market in the Smart Grid
Environment. S. N. Saxena [9] presented smart distribution grid from a new perspective of how the consumers (People) and different activities (Processes) of distribution companies are interconnected. In this paper, he gives recommendations for distribution companies related to their various roles (during planning and operation stages). The motivations that lead Indians to migrate to smart grids are higher technical and non-technical losses, a perpetual shortage of peak demand, human errors, and aging infrastructures [6].

The smart meter is a meter that can exchange data of consumption with the consumer and the distributor through a communication network. In 2009, Markus Weiss et al [10] carried out an analysis of possibility to connect smart meters with the mobile phone. It uses a system that architecture is based on three essential components including a smart meter, a gateway and a user interface to get the results in real-time and to measure the devices. In June 2018 Y. Wang et al [11] did a review on meters for the future Chinese grid. This study focuses on the capabilities of smart meters to be able to provide data reading, remote connection and disconnection as well as advanced control of the charge. Pol Van and E. Poll [12] analysed the impact or importance of smart metering in the Netherlands. In their article, they present the modelling of smart metering systems and the methods used. They place particular emphasis on security aspects and confidentiality. D. B. Avancini et al [13] reviewed smart meters in the evolution of the smart grid. They present the fact that the level of consumption of electric energy, ecological conditions and the implementation of advanced technologies allow the development of a new configuration of smart grid. The smart meters already used in some countries are presented in Table 1.

Table 1 Smart meters in some countries

\begin{tabular}{|c|c|}
\hline Country & Smart meter \\
\hline France & Linky, ISKRA_ME372/MT372 \\
\hline USA & ITRON, LANDIS, ZMAI 90 \\
\hline China & Hexing, ISKRA, Radar King \\
\hline England & ITRON, Linky, \\
\hline Germany & Linky, ITRON, kamstrup omnıpower \\
& \\
\hline
\end{tabular}

The smart meter periodically exchanges information with the utility company through the AMI (Automated Metering Infrastructure) network. The necessary bandwidth requested on this network is between 10 to $100 \mathrm{Kbps}$ and the communication technologies that can meet the need of the home network are ZigBee, Wi-Fi, Bluetooth, 6LoWPAN, and ZWave. But the majority of researchers consider ZigBee to be the most suitable technology [14]. The AMI's physical system consists of three networks WAN (Wide Area 
Network), NAN (Neighbourhood Area Network), and HAN (Home Area Network) also a workstation and enterprise data processing. The meters must have advanced functions such as the remote reading of interval data, remote connection and disconnection, advanced load control and interface with a HAN [15].

Knowing the problems of fraud, index reading errors and billing by estimation in our country, our article contributes to the reduction of energy losses through collaboration between energy distributors, the government and academics

This paper is organized as follows: section 2 provides the presentation of methods, section 3 presents and discussed the obtained roadmaps in short term, in the medium term and long term, for the deployment of the smart meter in Cameroon and also the agenda of the implementation of the main steps of these roadmaps.

\section{Methods}

Many roadmaps have been already proposed in many countries concerning the deployment of smart meter in distribution grid.

M. F. Khan et al [6] presented a roadmap for the deployment of smart meters for the Indian smart grid. In their article, they presented the main drivers of the smart grid dynamic, which are higher losses, a perpetual shortage of peak demand, human errors and aging infrastructure. They proposed an AMI communication architecture for smart meter, LAN / WAN communication over RF Mesh / PLCC / GPRS, a network management system (NMS) and a home network for the home control system.

Františ et al [16] presented a roadmap for smart metering in the Slovak republic. In their paper they presented the distribution network of some Europeans countries and particularly of Slovakia. They proposed an implementation of smart meter in higher voltage levels in collaboration with producers, operators of transmission network and distribution systems. They also implemented the automated meter reading (AMR) solution covering most significant points of supply and consumption.

Hawaiian Electric Companies [17] proposed to implement a smart grid roadmap in the distribution network of five islands of Hawaii and to achieve the AMI part in 2018. They presented the implementation of a smart grid on the distribution networks of the five islands. They achieved the AMI part of the smart grid with the ultimate goal of making the smart grid a beneficial reality for the State's electricity grid and for their customers. Their smart grid roadmap includes five main phases: Assessment (completed in 2008), planning (completed in 2013), demonstration (initial phase in early 2014), full implementation (from 2016 and beyond) and the value delivery.
The Asia Development Bank [18] presented a roadmap of smart metering in Nepal. Knowing all significant challenges due to inadequate power generation, poor distribution and transmission infrastructure resulting from years of underinvestment and delays in reforming the sector, resulting in inadequate policy and regulatory frameworks, they proposed within the framework of this article, to deploy smart meters and the associated computer systems to improve operational efficiency by establishing a transparent and real-time interface with customers.

Gevork B. Gharehpetian et al [19] presented a roadmap as well as the metering program concerning the Iranian smart grid. In their article, they proposed a roadmap for the technological development of the Iranian smart grid consisting of two documents recommended by the European Commission in particular: the Smart Grid Architecture Model (SGAM) which represents the aspects of interoperability and the way in which they are taken into account via an approach based on a domain, a zone and a layer; the JRC (Joint Research Center) or CCR (Common Center of Research) method, which has a technical management concept. Their roadmap for technology development has three parts: the development approach, prioritization of technologies, and determining the method of technology acquisition.

The analysis of the energy metering audit, the reports of the energy distribution company in Cameroon, the Cameroon energy development strategy documents allowed us to identify the problems which are facing the distribution network particularly the metering system. We then conducted interviews with staff from the Ministry of Water and Energy; the regulatory agency for the electricity sector; the structure in charge of electric energy distribution in Cameroon. The method used for these surveys was based on questioning. The results of the analysis of this survey show us that the implementation of smart metering is very needed in our country. Then, inspired by roadmaps already done in other countries, we elaborated our own taking into account our specificities.

\section{Results}

\subsection{First phase}

This first phase presents the various stakeholders involved in the national steering committee or steering committee as well as their missions. These stakeholders are made up of experts from public services, electricity regulatory bodies and representatives of ministries, academia, the Standards and Quality Agency, research, development, and industry. Table 2 gives us the roadmap for the first phase. 
Table 2. First phase of roadmap

\begin{tabular}{|c|c|c|}
\hline Organization & Members & Missions \\
\hline & $\begin{array}{c}\text { Ministry of Water and Energy } \\
\cdot \text { ARSEL } \\
\bullet \text { ENEO } \\
\text { - Independent power producers (IPP) }\end{array}$ & $\begin{array}{l}\text { - Develop an implementation plan for } \\
\text { smart meters and the smart grid, including } \\
\text { a strong focus on energy efficiency and } \\
\text { alternative energy sources; } \\
\text { - Develop recommendations for upgrades }\end{array}$ \\
\hline National Steering Committee & $\begin{array}{c}\text { Ministry of Posts and } \\
\text { Telecommunications } \\
\text { • CAMTEL } \\
\text { • Cybercrime cell } \\
\text { Standards and Quality Agency (ANOR) } \\
\text { The academics (universities and } \\
\text { research organizations). } \\
\text { The Consumer Union of Smart meters } \\
\text { and communication testing and } \\
\text { certification laboratories }\end{array}$ & $\begin{array}{l}\text { frameworks for smart metering and the } \\
\text { smart grid; } \\
\text { - Monitor the progress of smart metering } \\
\text { and smart grid implementation, } \\
\text { performing cost benefit analysis and } \\
\text { proposing corrective actions if expected } \\
\text { benefits are not achieved; } \\
\text { - The steering committee should include } \\
\text { representatives of market stakeholders, } \\
\text { the energy regulator, government } \\
\text { agencies, utilities, and others, to ensure a } \\
\text { holistic approach and strategy for the } \\
\text { deployment of smart metering. }\end{array}$ \\
\hline
\end{tabular}

The actual steering committee of this project is responsible for effectively monitoring all programs and highlighting the roles and responsibilities of the different parts. Indeed, it is recommended that a national supervisory committee or a steering committee involving the main actors for electricity be formed for the occasion. Figure 1 shows the organization chart of the steering committee.

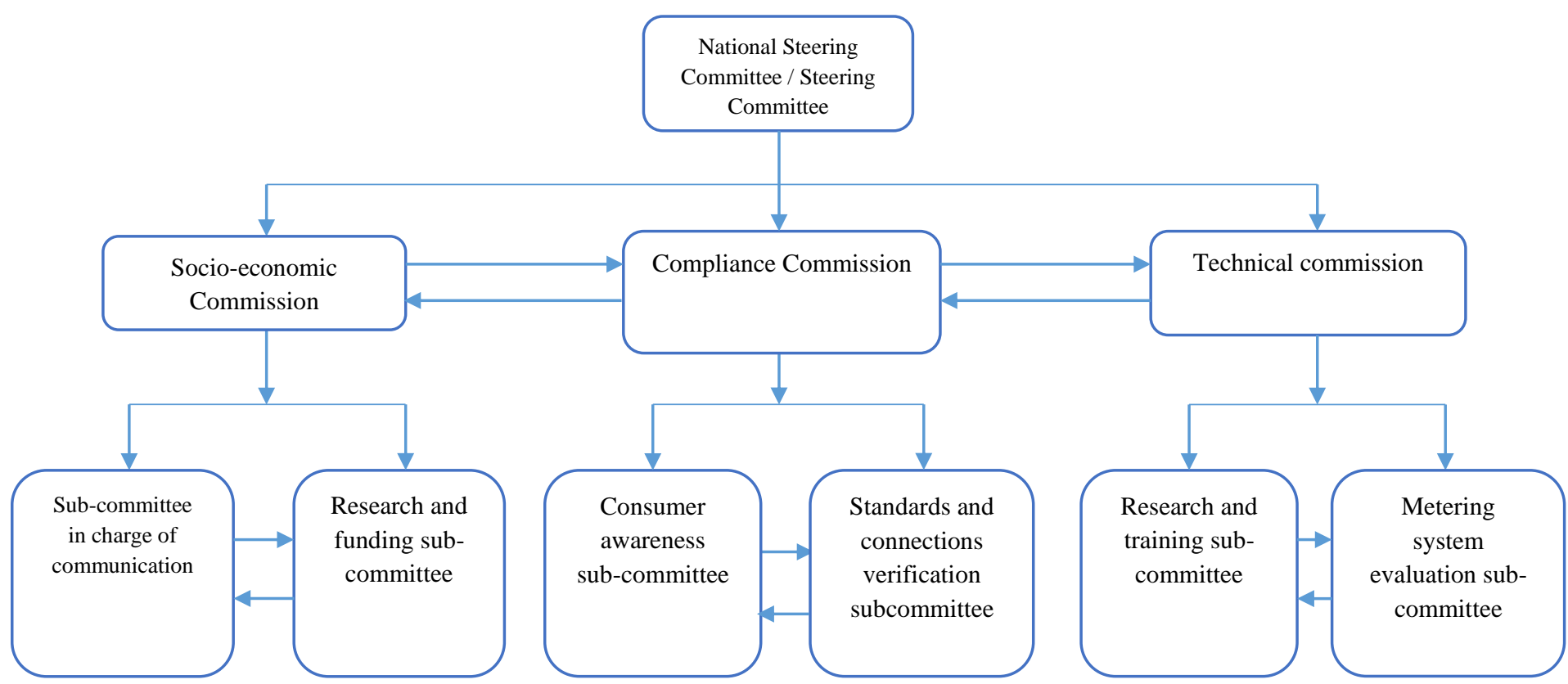

Fig. 1. Organizational chart of the steering committee

For most utilities, smart metering is a very complex project as it involves a transformation of both utility technology and processes. The main work elements of the steering committee that will allow Cameroon to migrate to smart metering are presented as follows:

Initial mission of the steering committee: 
- Develop and / or approve a national policy for the deployment of smart metering;

- Approve the objectives of this national policy, which are consistent with energy efficiency, and the objectives of using alternative energy sources.

Mission of the steering committee:

- Provide a strategic vision for political decisions;

- Ensure the successful implementation of smart meter projects;

- Promote and explore innovative business models;

- Provide a platform to ensure that the smart metering program is aligned with the vision of the Cameroonian government.

Mission of the technical team

The steering committee will also create technical teams to continue deliberations and reach consensus in key areas.

$>$ Sub-committee in charge of research and training:

- Provide training for agents;

- Look for partners;

- The establishment of special teams.

$>$ Counting system evaluation sub-committee:

- Check the accuracy of the measurement;

- Ensure the reliability of counting;

- Ensure data bi-directionality;

- Perform remote cuts and resets.

Mission of the socio-economic committee:

Its objective is to ensure communication of the implementation of smart meters; to seek funding.

Sub-committee in charge of communication

- Raise awareness among populations for this new counting system;

- Raise awareness among public authorities;

- Fundraising sub-committee;

- Look for investors;
- Look for partners and sponsors.

$>$ Mission of the Compliance Audit Committee

Its purpose is to: verify standards and connections; consumer awareness.

$>$ Standards and connections verification sub-committee:

- Check the conformity of the connections;

- Ensure compliance with the norms and standards in force.

The success of this deployment would require synergies from all the main stakeholders. To ensure the successful and efficient deployment of smart meters, we offer the following activities:

- Provide the executing agency with a database of consumers and assets, including regular updates;

- Cooperate with the executing agency during data validation;

- Support a consumer awareness campaign;

- Organize or provide all kinds of clearances, such as regulatory authorizations and work permits as well as regulatory support for the implementation of smart meter projects;

- Carry out a pre-audit of the available data in collaboration with the executing agency;

- Ensure safe and rapid access to all locations where smart meters and support equipment will be installed;

- Assign the required staff and provide them to accomplish the desired tasks.

\subsection{Second phase of roadmap}

Smart meters can be deployed either for specific consumers or for all consumers on the same departure. A roadmap for the second phase is established for the deployment of these smart meters. This roadmap is subdivided into three terms: short term, medium term and long term.

\subsubsection{Short-term deployment}

This phase is mainly for the deployment of smart meters among HV, big LV and LV subscribers in large cities. Table 3 shows the short-term deployment. 
INTERNATIONAL JOURNAL OF SMART GRID

F. YEM SOUHE et al., Vol.5, No.1, March, 2021

Table 3. Short-term deployment

\begin{tabular}{|c|c|c|c|c|}
\hline Steps & Duration & $\begin{array}{l}\text { Types of subscribers } \\
\text { concerned }\end{array}$ & Canvas & $\begin{array}{l}\text { Number of smart } \\
\text { meter }\end{array}$ \\
\hline Step 1 & $1-2$ years & Industries of large cities & $\begin{array}{l}\text { - Build the communication network } \\
\text { - Install the infrastructures (modem, RTU, } \\
\text { PMU, etc.) } \\
\text { Installation of HV meters }\end{array}$ & 20 \\
\hline Step 2 & $1-4$ years & $\begin{array}{l}\text { Big LV subscribers of large } \\
\text { cities }\end{array}$ & $\begin{array}{l}\text { - Build the communication network } \\
\text { - Install the infrastructures (modem, RTU, } \\
\text { PMU, etc.) } \\
\text { Installation of MV meters }\end{array}$ & 2000 \\
\hline Step 3 & $1-6$ years & LV subscribers of large cities & $\begin{array}{l}\text { - Build the communication network } \\
\text { - Install the infrastructures (modem, RTU, } \\
\text { PMU, etc.) } \\
\text { Installation of LV meters }\end{array}$ & 10000 \\
\hline
\end{tabular}

In the short term, we will install the HV, big LV and LV smart meters at subscribers in large cities: Yaounde, Douala and Bafoussam. We start by installing 5000 smart meters in Douala, 3000 in Yaounde and 2000 in Bafoussam.
Here we focus on the deployment of smart meters among big LV and LV subscribers in medium cities. Table 4 shows the medium-term deployment.

\subsubsection{Medium term deployment}

Table 4. Medium-term deployment

\begin{tabular}{|c|c|c|c|c|}
\hline Steps & Duration & $\begin{array}{l}\text { Types of subscribers } \\
\text { concerned }\end{array}$ & Canvas & $\begin{array}{l}\text { Number of smart } \\
\text { meter }\end{array}$ \\
\hline Step 1 & $1-11$ years & $\begin{array}{l}\text { Big LV subscribers of medium } \\
\text { cities }\end{array}$ & $\begin{array}{l}\text { - Build the communication network } \\
\text { - Install the infrastructures (modem, RTU, } \\
\text { PMU, etc.) } \\
\text { Installation of MV meters }\end{array}$ & 5000 \\
\hline Step 2 & $\begin{array}{l}1-20 \\
\text { years }\end{array}$ & LV subscribers of medium cities & $\begin{array}{l}\text { - Build the communication network } \\
\text { - Install the infrastructures (modem, RTU, } \\
\text { PMU, etc.) } \\
\text { Installation of LV meters }\end{array}$ & 1000000 \\
\hline
\end{tabular}

In the medium term, we will install the $\mathrm{HV}$, big LV and LV smart meters at subscribers in medium cities: Limbe, Ebolowa, Betook, Ngaoundere, Buea and Bamenda.

\subsubsection{Long term deployment}


Our target is to the deployment of smart meters among big LV and LV subscribers in small cities. Table 5 shows the Table 5. Long-term deployment long-term deployment.

\begin{tabular}{|l|l|l|l|l|}
\hline Steps & Duration & $\begin{array}{l}\text { Types of subscribers } \\
\text { concerned }\end{array}$ & $\begin{array}{l}\text { Canvas } \\
\text { meter }\end{array}$ & 100000 \\
\hline Step 1 & $\begin{array}{l}1-35 \\
\text { years }\end{array}$ & $\begin{array}{l}\text { Big LV subscribers of smaller } \\
\text { cities }\end{array}$ & $\begin{array}{l}\bullet \text { Build the communication network } \\
\text { PMU, etc.) }\end{array}$ & Installation of MV meters \\
\hline Step 2 & $1-50$ & LV subscribers of smaller cities & $\bullet$ Build the communication network & 3000000 \\
& & & $\begin{array}{l}\text { Install the infrastructures (modem, RTU, } \\
\text { PMU, etc.) }\end{array}$ & Installation of LV meters \\
\hline
\end{tabular}

In the long term, we will install the HV, big LV and LV smart meters at subscribers in medium cities: Maroua, Garoua, Ngaoundere; and cover all territory of country.

These deployments will be carried out according to the schedule of the structure in charge of energy distribution and the steering committee.

\section{Conclusion}

This article is a proposal for the deployment of smart meters in Cameroon. We have presented the classical distribution network and classical meter. We also presented the smart grid and the smart meter. Then we proposed our communication system which is a GSM communication network for exchanging data through the mobile phone. We also provide the operational roadmap of the smart meter deployment. This roadmap is established on two phases in particular: the first phase which consists of a reflection committee and the second phase which is based on the deployment on three stages (short term, medium-term and long term). In particular: in short term, we provide smart meters in large cities for 1 to 6 years; in the medium, we provide smart meters in medium cities for 1 to 20 years and in long term, we provide smart meters in smaller cities.

\section{Acknowledgements}

The Authors thanks the department of electrical engineering for the participation in this research.

\section{References}

[1] Studi International, Final report of the project, Application study, pp. 1-52, 2014. (Standards and Reports)
[2] ENEO, Eneo annual report, 2018. (Standards and Reports)

[3] S. Bimenyimana, "Traditional Vs Smart electricity metering systems: a brief overview", an international Peer-reviewed Journal, vol. 46, pp. 2-8, 2018. (Article)

[4] B. A. Abedalsalam, A. Nasiri, I. Stamenkovic, "Foundational Support Systems of the Smart Grid: State of the Art and Future Trends", INTERNATIONAL JOURNAL of SMART GRID, Vol. 2, No. 1, 2018. (Article)

[5] S. Kaplantzis, Y. A. Sekercioglu, "Security and smart metering", In European Wireless 18th European Wireless Conference, Vol. 30, No. 3, pp. 1-8. (Article)

[6] M. F. Khan, A. Jain, V. Arunachalam, A. Paventhan, "Roadmap for smart metering deployment for India smart grid”, IEEE journal, vol. 2, pp. 1-5, 2014. (Article)

[7] D. B. Avancini, J. Rodrigues, S. G. Martins, R. A. Rabelo, J. Al-Muhtadi, P. Solic, "Energy meter's evolution in smart grids: A review", In Journal of Cleaner production, vol. 2, pp. 1-7, 2019. (Article)

[8] S. N. Saxena, "Smart Distribution Grid - and How to Reach the Goal", INTERNATIONAL JOURNAL of SMART GRID, Vol. 3, No. 4, 2019. (Article)

[9] S. N. Saxena, "Trilemma of Smart Distribution Grid: People, Processes and Environment", INTERNATIONAL JOURNAL of SMART GRID, Vol. 4, No.1, 2020. (Article)

[10] M. Weiss, F. Mattern, H. Feedback, Connecting smart meters with mobile phones, Cambridge-UK, 2009, pp. 132. (Book)

[11] Y. Wang, H. Qiu, Y. Tu, Q. Liu, Y. Ding, W. Wang, “A review of smart metering for future Chinese grids", 
Energy procedia, vol. 217, pp. 1194-1199, 2018. (Article)

[12] A. Pol Van, E. Poll, "Smart metering in the Netherlands: what, how, and why", Digital security group, vol. 2, pp. 1-10, 2019. (Article)

[13] D. B. Avancini, J. J. P. C. Rodrigues, S. G. B. Martins, "Energy meter's evolution in smart grids: A review", Journal of cleaner production, vol. 3, pp. 1-14, 2019. (Article)

[14] Asia Development Bank, Roadmap of smart metering in Nepal, 2018, pp. 1-25. (Book)

[15] K. Murat, "Communication network requirements for major smart grid applications in HAN, NAN and
WAN", Computer Networks, vol. 67, pp. 74-88, 2014. (Article)

[16] J. E. Františ, M. Ščepánek, A. Beláň, I. Chrapčiak, P. Chochol, "a roadmap for smart metering in the Slovak republic", Energy and environment, vol. 26, No. 1, pp. 35-52, 2015. (Article)

[17] HEC, Smart Grid Roadmap and Business Case, Hawaien electric companies, 2014, pp. 1-134. (Book)

[18] Asian development bank, smart metering road map for Nepal, Philippines, 2018, pp. 1-50. (Book)

[19] G. B. Gharehpetian, M. S. Naderi, H. Modaghegh, "Iranian smart grid: road map and metering program", Journal of technology, Vol. 3, pp. 1-48, 2018. (Article) 